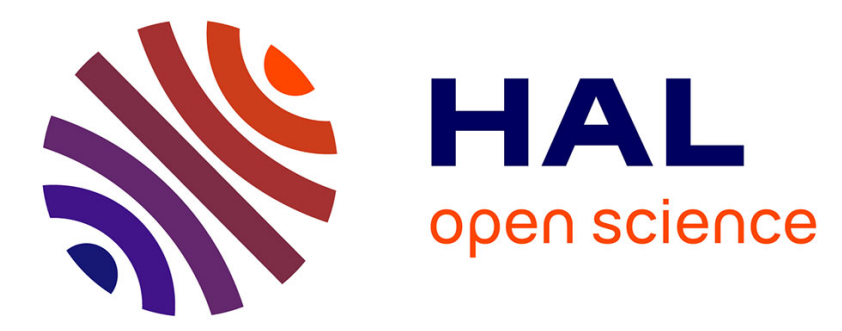

\title{
The mutations and potential targets of the forkhead transcription factor FOXL2
}

L. Moumné, F. Batista, B. Benayoun, J. Nallathambi, M. Fellous, P. Sundaresan, R.A. Veitia

\section{- To cite this version:}

L. Moumné, F. Batista, B. Benayoun, J. Nallathambi, M. Fellous, et al.. The mutations and potential targets of the forkhead transcription factor FOXL2. Molecular and Cellular Endocrinology, 2008, 282 (1-2), pp.2. 10.1016/j.mce.2007.11.006 . hal-00531961

\section{HAL Id: hal-00531961 https://hal.science/hal-00531961}

Submitted on 4 Nov 2010

HAL is a multi-disciplinary open access archive for the deposit and dissemination of scientific research documents, whether they are published or not. The documents may come from teaching and research institutions in France or abroad, or from public or private research centers.
L'archive ouverte pluridisciplinaire HAL, est destinée au dépôt et à la diffusion de documents scientifiques de niveau recherche, publiés ou non, émanant des établissements d'enseignement et de recherche français ou étrangers, des laboratoires publics ou privés. 


\section{Accepted Manuscript}

Title: The mutations and potential targets of the forkhead transcription factor FOXL2

Authors: L. Moumné, F. Batista, B. Benayoun, J. Nallathambi, M. Fellous, P. Sundaresan, R.A. Veitia

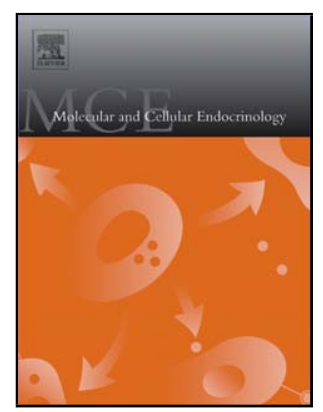

PII:

S0303-7207(07)00428-5

DOI: doi:10.1016/j.mce.2007.11.006

Reference: MCE 6755

To appear in: $\quad$ Molecular and Cellular Endocrinology

Please cite this article as: Moumné, L., Batista, F., Benayoun, B., Nallathambi, J., Fellous, M., Sundaresan, P., Veitia, R.A., The mutations and potential targets of the forkhead transcription factor FOXL2, Molecular and Cellular Endocrinology (2007), doi:10.1016/j.mce.2007.11.006

This is a PDF file of an unedited manuscript that has been accepted for publication. As a service to our customers we are providing this early version of the manuscript. The manuscript will undergo copyediting, typesetting, and review of the resulting proof before it is published in its final form. Please note that during the production process errors may be discovered which could affect the content, and all legal disclaimers that apply to the journal pertain. 
The mutations and potential targets of the forkhead transcription factor FOXL2

L. Moumné ${ }^{1,2,3}$, F. Batista ${ }^{1,2,3}$, B. Benayoun ${ }^{1,2,3}$, J. Nallathambi ${ }^{4}$, M. Fellous ${ }^{1,2,3}$, P. Sundaresan ${ }^{4}$, R. A. Veitia ${ }^{1,2,3}$.

1. Institut Cochin, Université Paris Descartes, CNRS (UMR 8104), Paris, France.

2. Inserm, U567, Paris, France.

3. Université Paris VII, Paris, France.

4. Department of Genetics, Aravind Medical Research Foundation, Aravind Eye Hospital, Madurai, India.

Correspondence to : veitia@,cochin.inserm.fr

Equipe 21. Institut Cochin. Faculté de Médecine.

24 rue du Faubourg Saint Jacques.

75014 Paris.

Phone: 33144412317

Fax: 33144412302 


\begin{abstract}
.
Mutations of FOXL2, a gene encoding a forkhead transcription factor, have been shown to cause the blepharophimosis-ptosis-epicanthus inversus (BPES) syndrome. This genetic disorder is characterized by eyelid and mild craniofacial abnormalities that can appear associated with premature ovarian failure. FOXL2 is one of the earliest ovarian markers and it offers, along with its targets, an excellent model to study ovarian development and function in normal and pathological conditions. In this review we summarize recent data concerning FOXL2, its mutations and its potential targets. Indeed, many mutations have been described in the coding sequence of FOXL2. Among them, polyAlanine expansions and premature nonsense mutations have been shown to induce protein aggregation. In the context of the ovary, FOXL2 has been suggested to be involved in the regulation of cholesterol and steroid metabolism, apoptosis, reactive oxygen species detoxification and inflammation processes. The elucidation of the impact of FOXL2 mutations on its function will allow a better understanding of the pathogenic mechanisms underlying the BPES phenotype.
\end{abstract}




\section{Introduction.}

Premature ovarian failure (POF) is a disease affecting 1 to $3 \%$ of women before the age of 40 years. POF can occur in syndromic forms or can be isolated (non syndromic) and patients may present a primary or secondary amenorrhea, depending on the age of occurrence. It is characterized by increased levels of gonadotrophins and decreased levels of steroids. POF may result from a decrease in the primordial follicle pool, increased or accelerated follicular atresia, alteration of the recruitment of the dominant follicle and interruption of the maturation of the follicles. Infertility is usually present and can be so far treated by ovum donation.

There are several arguments in favor of a genetic etiology of POF. The existence of familial cases, which represent 10 to $15 \%$ of all POF cases, has already allowed the identification of disease loci (Aittomaki et al., 1995, Christin-Maitre et al., 1998). The most frequent anomalies are chromosome $\mathrm{X}$ alterations, such as monosomy, deletions and $\mathrm{X}$-autosomal translocations. Some studies have defined large critical regions (see for example: Powell et al., 1994) and the implication in POF of several candidate genes within these regions is still under study (Bione et al., 1998; Prueitt et al., 2000; Goswami and Conway, 2005). Autosomal mutations have also been identified in POF patients. For example, mutations in the FSH receptor gene (Aittomaki et al., 1995; Touraine et al., 1999) have been described in non-syndromic cases of POF. On the other hand, POF can be associated with syndromic cases as it is the case of ataxia telangiectasia where the ATM gene is mutated, and Blepharophimosis Ptosis Epicanthus Inversus Syndrome (BPES), induced by FOXL2 mutations. Animal models have corroborated the implication of these genes in POF (Barlow et al., 1996, Dierich et al., 1998). Unfortunately, for most POF patients, the etiology of the disease is unknown. Therefore, this complex disorder still requires in depth investigation.

The focus of this review is the gene FOXL2, whose mutations occur either sporadically or as an inherited "autosomal dominant" disorder responsible for BPES which is a genetic disease leading to complex eyelid malformation and other mild craniofacial anomalies. Two forms of the syndrome have been described: in type I BPES, eyelid and craniofacial malformations are associated with ovarian dysfunction leading to POF, whereas in type II BPES, the craniofacial phenotype appears isolated (Zlotogora et al., 1983). FOXL2 is a single-exon gene encoding a forkhead/winged helix (fkh) transcription factor (Crisponi et al., 2001). The structure of the fkh domain in a complex with a target DNA has been resolved for HNF3 $\gamma /$ FOXA3 (Clark et al., 1993). The fkh is composed of three alpha helices and two characteristic large loops or 
"wings". At the C-terminus of the fkh domain, the FOXL2 protein contains a polyalanine (polyAla) tract of unknown function. The FOXL2 coding sequence is highly conserved in vertebrates and the number of alanine residues in the polyAla tract is strictly conserved among the mammals studied, suggesting the existence of functional or structural constraints (Cocquet et al., 2002; Cocquet et al., 2003).

Immunohistochemical studies using two polyclonal antibodies directed against mammalian FOXL2 have shown that FOXL2 is a nuclear protein present in foetal and adult peri-occular and ovarian follicular cells. The last fact is corroborated by the rather strong expression in extra-ocular muscles (i.e. superior rectus) as judged from microarray data from the Gene expression Omnibus (GEO at http://www.ncbi.nlm.nih.gov/sites/entrez, experiment GDS525). These observations are compatible with the BPES phenotype and with its role as a transcription factor (Cocquet et al., 2002). However, an exploration of the GEO database suggests a much wider expression profile. RNA is detected in a panoply of tissues and cell lines (hematopoietic stem cells/GDS1803, activated macrophages/GDS2041, colon cancer at different stages/GDS756 and GDS1780, splenocytes/GDS2092, leukemia cells/GDS1324, etc).

Foxl2 is also expressed in the pituitary, mostly in gonatotrope and thyrotrope cells (Ellsworth et al., 2006). Foxl2 is expressed early during development in the mouse pituitary gland (Ellsworth et al., 2006), and seems to play an important role in organogenesis. Human BPES patients do not display any well documented "pituitary" phenotype. This could result from a gene dosage effect: a single functional allele might be sufficient in most cases to accomplish its function in the pituitary.

As mentioned above, FOXL2 is a nuclear protein. Indeed, sequence analysis shows that it contains an arginine/lysine(RK)-rich sequence at the C-ter of the fkh domain (i.e. RRRRRMKR) that might function as a nuclear localization signal (NLS). Moreover, this potential NLS is conserved between FOXL2 and FOXE1. The latter contains two NLS in the fkh domain, one at the Nter and the other at the Cter (Romanelli et al., 2003). The functionality of the potential NLS of FOXL2 has been studied using two constructs containing the Nterminus of FOXL2 including (NLS+) or one excluding the putative NLS (NLS-), fused to the green fluorescent protein (GFP). Transfections of these constructs have shown that the NLS+ protein localizes exclusively in the nucleus whereas NLS- one localizes both in the nucleus and the cytoplasm. This result shows that the classical RK-rich sequence is a strong NLS. However, it points to the existence of another sequence with some NLS activity. Sequence analysis failed 
to reveal another RK-rich sequence in the N-ter of FOXL2. A series of deletion constructs has allowed us to map the non-conventional NLS to the segment between residues 125-144 (i.e. KGNYWTLDPACEDMFEKGNY).

Two independent Foxl2 ${ }^{-/-}$mice models have been produced. In one of them, granulosa cells failed to make the transition from the squamous to the characteristic cuboidal morphology, which occurs when primordial follicles transform into primary follicles. This leads to the absence of primary and secondary follicles (Schmidt et al., 2004). Oocytes grow to nearly full size, but a massive follicular atresia was observed in the absence of cuboidal granulosa cells. An accelerated depletion of the follicular pool was obvious at 8 weeks after birth. At the molecular level, in situ hybridization analysis showed that the expression of Amh and activin$\beta A$, which are known to play a role in the inhibition of follicular recruitment, was markedly diminished. Consequently, two weeks after birth most oocytes expressed $G d f 9$, meaning that they have started folliculogenesis. These results altogether show that Foxl2 is essential for granulosa cell differentiation, and suggest that granulosa cell function is not only crucial for oocyte growth but also in the maintenance of some follicular quiescence. The other available mouse model (Uda et al., 2004), displays defects comparable to those observed in BPES patients. The most important non-ovarian phenotype consists of a severe eyelid hypoplasia, probably due to the lack of expression of FOXL2 in the periocular tissues. Interestingly, the KO mice have small size which could be due to a pituitary defect. If this is so, research should focus on the thyrotrope (TSH-producing) cells because somatotropes (GH-producing) do not express Fox12 (see Ellsworth et al., 2006). Concerning the ovary, they were found reduced in size and disorganized. The authors gathered evidence for the induction of the granulosa cell differentiation program, as some of those cells expressed the proliferation marker Ki67, but this induction was subsequently impaired. In agreement with the findings of Schmidt et al. at 2 weeks, Uda et al. found that normal mice showed multiple layers of granulosa cells surrounding the oocyte, while mutant mice had only a single layer of flattened pre-granulosa, without mitotic activity. In contrast to the Foxl2 $2^{-/}$model of Schmidt et al., no apoptosis was found in these flattened granulosa cells at 8 weeks. In addition, somatic cell lineages failed to develop around the oocyte from the primordial follicle formation, suggesting that Foxl2 is required during this early process. Taken together the data from these mouse models suggest that the ovarian failure associated with BPES results from a malfunction of granulosa cells during follicle formation, which leads to deregulated oogenesis. In vertebrates, FOXL2 is one of the earliest known markers of ovarian differentiation (Cocquet et al., 2002). Thus, it may 
play a role in the early stage of development of the ovarian somatic compartment. As it is still strongly expressed in postnatal and adult follicular cells, it may also play a role in follicle development and/or maintenance during fertile life.

\section{Mutations affecting the $F O X L 2$ locus.}

A large spectrum of mutations has been detected in the FOXL2 locus (details in the human FOXL2 mutation database at http://medgen.ugent.be/foxl2). Intragenic mutations have been found in about $70 \%$ of BPES patients (De Baere et al., 2001, 2003). These mutations are basically located in the open reading frame (ORF). They include premature stop codons, missense mutations, expansions of the region encoding the polyAla domain and frameshift mutations leading to a shorter or longer protein. Mutations expected to lead to a truncated protein are often responsible for BPES type I. In contrast, mutations leading to elongated proteins more often lead to BPES type II. Missense mutations, essentially located in the fkh domain, are responsible for both types of BPES. Thirty percent of the mutations detected in the ORF result in an expansion of the polyAla of FOXL2, from 14 to 24 residues, and are mainly responsible for BPES type II (Crisponi et al., 2001, De Baere et al., 2001, 2003). Genomic rearrangements have been found in $16 \%$ of patients, including microdeletions encompassing FOXL2, translocations and deletions involving long-range non-genic conserved sequences far upstream and downstream of FOXL2 (Beysen et al., 2005).

\section{The polyAla expansion leads to protein aggregation and its sequestration in the cytoplasm.}

BPES is one of the nine known diseases caused by an expansion of a polyAla domain. This class of disorders includes synpolydactily type II (HOXD13; Muragaki et al., 1996), cleidocranial dysplasia (RUNX2; Mundlos et al., 1997), holoprosencephaly (ZIC2; Brown et al., 2001), Hand-foot-genital syndrome (HOXA13; Utsch et al., 2002), mental retardation with growth hormone deficiency (SOX3; Laumonnier et al., 2002), Partington syndrome ( $A R X$; Stromme et al., 2002), congenital central hypoventilation syndrome (PHOX2B; Amiel et al., 2003) and occulopharyngeal muscular dystrophy (PABPN1; Brais et al., 1998). All these genes, with the exception of $P A B P N 1$, encode transcription factors involved in developmental 
processes. In 2004, little was known about the pathogenesis of the polyAla expansion, beyond the fact that such an expansion in $P A B P N 1$ induced protein aggregation and nuclear inclusion (Calado et al., 2000). This type of mutation is supposed to induce a toxic gain of function like in the case of polyglutamine (polyGln) expansions (Paulson, 1999). Indeed, polyGln expansions are the cause of several neurological disorders including Huntington disease. It has been proposed that polyGln expansion leads to protein aggregation and nuclear inclusion inducing neuronal toxicity. However, the toxicity of polyAla and polyGln aggregates still remains unclear (Paulson, 1999).

Transfection experiments in COS-7 and HeLa cells, have shown that an expansion of +10 alanines induces a dramatic mislocalisation of FOXL2 and strong aggregation. The wild type (WT) protein localized exclusively in the nucleus in a diffuse manner, consistent with its function as a transcription factor (Figure 1). In contrast, $80 \%$ of cells transfected with the mutant construct displayed a strong cytoplasmic staining and both cytoplasmic and nuclear aggregation. It is thus possible that polyAla expansion leads to a misfolding that prevents the protein to localize in the nucleus and to ensure its transcriptional activity. Moreover, even when the protein can localize in the nucleus, it aggregates and cannot interact with its target promoters. Interestingly, co-expression of the WT and the mutant construct induced a partial retention of the normal protein in the aggregates, suggesting a possible dominant negative effect of the expanded protein (Caburet et al., 2004). This deserves further analyses. The aggregation phenomenon has been studied in other polyAla containing transcription factors. Albrecht and colleagues have shown that an increase of the polyAla repeat of Hoxd13 above 22 residues is associated with a shift in its localization from the nucleus to the cytoplasm, where it forms aggregates. These aggregates are sensitive to the efficacy of proteasomal degradation and the chaperone system. They also observed this phenomenon for polyAla expansions in SOX3, RUNX2 and HOXA13. Moreover, WT Hoxd13 colocalized with the expanded protein in the aggregates. In vivo studies of polyAla expansion using a natural mouse mutant spdh showed a reduction of the mutant Hoxd13 and a cytoplasmic localization of the protein, somehow recapitulating the results obtained in the COS-7 cells (Albrecht et al., 2004). These observations are consistent with the results obtained with FOXL2 and point to a common pathogenic mechanism. A similar behavior has been observed for PHOX2B in cellular models (Bachetti et al., 2005; Trochet et al., 2005). In both studies, the authors have demonstrated that expanded PHOX2B cannot activate its transcriptional targets suggesting a loss of function of the expanded protein. Nasrallah and colleagues have concomitantly shown that a polyAla 
expansion in Arx transcription factor forms intranuclear inclusions and results in increased cell death suggesting a toxic effect (Nasrallah et al., 2004). Thus, it appears that this expansion lead to cellular toxicity as it was suggested for PABPN1. However, in the case of FOXL2 (and probably other factors) this hypothesis seems unlikely. The polyAla expansion in FOXL2 basically leads to the same palpebral phenotype as amorphic alleles (i.e. complete deletion of the gene) and does not induce ovarian dysfunction in most cases. It probably induces a developmental defect of the eyelids rather than a degenerative process. In spite of the possible dominant negative effect suggested by the cotransfection experiments, the most probable hypothesis is that expanded FOXL2 acts as a hypomorphic allele that has retained some activity in the ovary but not enough in the eyelids. This different behavior can be due to a differential aggregation in both tissues or a difference in the settings of the target promoters in both tissues (i.e. some target promoters in the eyelids may require a higher FOXL2 concentration).

Recently, the first homozygous FOXL2 mutation leading to a polyAla expansion of +5 residues (FOXL2-Ala19) has been described (Nallathambi et al., 2007). This novel mutation segregates in an Indian family where heterozygous mutation carriers are unaffected whereas homozygous individuals have the typical BPES phenotype, with proven POF in one female. Expression of the FOXL2-Ala19 protein in COS-7 cells showed a cytoplasmic retention in 15 $\%$ of cells. However, only weak cytoplasmic and nuclear aggregation was detectable with the resolution of light microscopy. These results show that the pathogenicity of a polyAla expansion depends on both the dose and the length of the expansion. Concerning, the palpebral phenotype in heterozygotes, a small expansion (Ala19) does not induce any defect whereas a longer one (Ala24) induces a full phenotype. In the ovary, the Ala19 expansion induces ovarian dysfunction when homozygous, suggesting that it acts as a hypomorphic allele. Interestingly, some cases of heterozygous Ala24 and one case of Ala26 (Raile et al., 2005) expansion have been associated with ovarian dysfunction.

To better understand the mechanisms of pathogenicity of the polyAla expansion, it would be interesting to explore i) the impact of the polyAla expansions on the activity of FOXL2 and ii) the effect of the aggregates on cellular physiology. To approach the first question, promoter reporter systems allow the functional analysis of FOXL2 (Pisarska et al., 2004; Ellsworth et al., 2003; Pannetier et al., 2006). Moreover, many potential target genes of FOXL2 have been recently identified (Batista et al., 2007; discussed later). The effect of polyAla expansion on these genes can be studied using transfection, microarrays and quantitative PCR. Notably, it will be interesting to assess whether the transcriptional impact of the polyAla expansion 
depends on the nature of the promoter. Indeed, theory predicts that different target promoters will have different sensitivities to decreased amounts of available/"soluble" FOXL2 (Veitia et al., 2003). A computational analysis of promoters displaying high-versus-low sensitivity to FOXL2 concentration might shed light on the molecular basis of this difference (i.e. differences in the number of FOXL2 binding sites or in sites for potential partners?). Microarrays experiments will allow the identification of genes activated or repressed by the presence of aggregated protein. The genes that are expected to display altered expression patterns will be: i) direct and indirect FOXL2 targets and ii) genes whose products are somehow involved in the aggregation process (i.e. proteasome subunits, ubiquitinylation pathway members, chaperons, etc). These latter genes are likely to be modifiers of the phenotype or co-aggregate with the mutant proteins. Indeed, in a similar study involving a mutant PABPN1 protein, the products of these genes were found in the aggregates (Corbeil-Girard et al., 2005).

\section{A premature stop codon in $F O X L 2$ results in $\mathrm{N}$-terminally truncated products that aggregate massively in the nucleus.}

Translation of an ORF bearing a premature stop codon leads to N-terminally truncated products resulting from three different mechanisms: translational re-initiation, leaky scanning of the ribosome or internal ribosomal entry (IRE). Translational re-initiation corresponds to a situation in which the ribosomes recognize the 5 ' end of the transcript, initiate translation at the first AUG, terminate at the premature stop codon and, without dissociating from the transcript, re-initiate translation at a downstream AUG. This leads to the production of a small peptide corresponding to the expected $\mathrm{N}$-term region (standard initiation) as well as an N-terminally truncated product resulting from the internal re-initiation. Leaky scanning corresponds to a situation in which some ribosomes bypass the first initiation codon and initiate translation at a downstream AUG. This mechanism occurs essentially when the first initiation codon does not lie within a Kozak consensus sequence (presence of pyrimidine in position -3 and +4 ; Kozak, 1987, 1989). These two mechanisms are Cap-dependent. In contrast, IRE (Internal Ribosomal Entry) can occur anywhere in the transcript in a Cap-independent manner at an initiation site called IRES (Internal Ribosomal Entry Site) (Hellen et al., 2001). In all cases, initiation efficacy at an internal start codon is supposed to be better if the AUG lies within a Kozak consensus sequence (i.e. GCC AUG G; Kozak, 1987). There is a growing number of genes for 
which internal translational initiation following premature stop codon has been described, demonstrating the importance of this phenomenon.

Recent studies have demonstrated that a premature stop codon in FOXL2 allows translational re-initiation at an internal AUG (AUG65) and leads to the production of an N-terminally truncated protein that aggregate massively in the nucleus. Analysis of the protein sequence reveals that the truncated product is devoid of 18 amino acids of the fkh domain. Comparisons of the amino-acid sequences of FOXA3 and FOXL2 reveal that six out of the eighteen lacking amino acids belong to the first helix of the forkhead. This suggests that a perturbation of the first helix may induce misfolding of the protein leading to its aggregation.

The mechanism of re-initiation is dependent on the position of the nonsense mutation. Several mutations at different positions within the ORF of FOXL2 have been tested showing that a stop codon located upstream of codon 31 leads to re-initiation whereas a stop located downstream of codon 41 does not (Moumné et al., 2005). This result strongly suggests a positional effect of the mutation and defines a "critical" position located between 31 and 41 that modulates translation reinitiation. This position effect may be explained by two alternative hypotheses: i) the longer the region that has been translated the weaker the chances of restarting translation or ii) there must be a minimum distance between the premature stop and the next AUG in a good Kozak environment for successful re-initiation. However, in the case of the ATRX gene, the mutation Q37X leads to translation restart at AUG40 (see below, Howard et al., 2004), which suggests that there is no absolute need of a minimum distance, supporting the first hypothesis.

Alternative translation initiation by the mechanisms outlined above has been proposed to explain why premature stop codons can result in mild forms of several diseases compared to amorphous mutations. In this context, two examples of IRE have been described. In cases of adenomatous polyposis coli and Nijmegen breakage syndrome, IRE allows the production of truncated and partially functional proteins in patients carrying frameshift deletions leading to premature termination in $A P C$ and NBS1 genes respectively (Heppner Goss et al., 2002; Maser et al., 2001). In both cases, the presence of an IRES is well documented. In other cases of phenotypic attenuation in the presence of premature nonsense mutations, the mechanism by which internal translational initiation occurs (IRE, re-initiation or leaky scanning) is less clear. In the cases of $A T R X$ (X-linked syndromal mental retardation) (Howard et al., 2004), DAX1 (adrenal hypoplasia congenita) (Ozisik et al., 2003) and PEX12 (peroxysome-biogenesis disorders) (Chang et al., 1998), the premature termination occurs very early, at positions 37, 37 
and 8 respectively. In $D A X 1$, the N-terminally truncated product resulting from internal translational initiation is also faintly visible when the WT protein is translated suggesting that the ribosome can bypass the first AUG and initiate translation at a downstream site (leaky scanning). In contrast, in ATRX and PEX12, the WT alleles do not produce the N-terminally truncated product in vivo suggesting a re-initiation, as it is likely the case for FOXL2. It is worth noticing that these positions are located upstream or near the critical region defined for FOXL2 within which the stop must be located to ensure re-initiation. More recently a premature termination due to a frameshift in the $N E M O$ gene has been described as a hypomorphic allele rather than amorphic (Puel et al., 2006). The internal initiation occurs upstream of the stop codon and leads to a truncated product also observed with the WT allele suggesting a leaky scanning or IRE rather than re-initiation. Obviously, the ability of Nterminally truncated products to attenuate the phenotype depends on the importance of the Nterminal portion for protein function. In some cases, premature termination leads to a severe phenotype in spite of internal translational initiation. This is the case of the androgen receptor $(A R)$ gene in which the $\mathrm{Q} 60 \mathrm{X}$ mutation leads to an $\mathrm{N}$-terminally truncated product and a complete testicular feminization phenotype (Zoppi et al., 1993). The ability of N-terminally truncated products to attenuate the phenotype may also depend on the expression level of the truncated product. Indeed, in all documented cases the truncated protein is expressed at a lower level compared to the WT. A reduced level of expression may result either from a decreased level of the mutant mRNA or from a reduced efficiency of translation starting at the internal site. Indeed, premature nonsense mutations are known to induce the Nonsense-Mediated mRNA Decay (NMD) in multi-exon genes (Culbertson, 1999; Wilkinson et al., 2002). However, in all cases described above where mRNA level has been tested, no decrease has been found. Moreover, translation re-initiation has been shown to abrogate NMD in mammalian cells (Zhang et al., 1997). As a single-exon gene, FOXL2 is not expected to be a target of NMD and the N-term truncated product is expressed at about $25 \%$ of the wild-type level, which is substantial.

The impact of N-ter truncated FOXL2 on the BPES phenotype is difficult to assess because of the lack of patients carrying mutations leading to reinitiation (the most 5' stop mutation is located in 53; Ramirez-Castro et al., 2002). However, no phenotype attenuation is expected because the truncated FOXL2 strongly aggregates in the nucleus and partially localizes in the cytoplasm (Figure 1). 
Given the propensity of FOXL2 to aggregation, it would be interesting to study the effect of other kinds of mutations (i.e. missense mutations in the fkh) on the solubility and localization of the protein.

\section{The targets of FOXL2}

Despite the importance of FOXL2 in ovarian development and maintenance, only a few transcriptional targets of FOXL2 have been described so far (Pisarska et al., 2004; Pannetier et al., 2006). In the context of the pituitary, FOXL2 seems to stimulate the expression of the gonadotropin-releasing hormone $(\mathrm{GnRH})$ receptor. The secretion of Follicle Stimulating Hormone (FSH) and Luteinizing Hormone $(\mathrm{LH})$ by gonadotrope cells is triggered by the binding of GnRH secreted by the hypothalamus to its receptor on gonadotrope cells. The gonadotrophin secretory response is a function of the amount of GnRH secreted, but also of the amount of GnRHR expressed at the plasma membrane of gonadotropes. The GnRHR activating sequence (GRAS) is a regulatory motif of the GnRHR promoter, composed of three partially overlapping transcription factor-binding sites recognized by a complex containing Smad3, AP1 and Fox12 (Ellsworth et al., 2003). Each of the complex components interacts directly with its target sequence inside the GRAS, and is necessary, though not sufficient, for activation of the GnRHR gene transcription, at least in the $\alpha$-T3 gonadotrope cell line (Ellworth et al., 2003).

Fox12 expression precedes glycoprotein hormone $\alpha$-subunit ( $\alpha$-GSU, common subunit to FSH, LH and TSH) expression in the pituitary suggesting that the $\alpha$-GSU gene is a downstream target of FOXL2. Indeed it has been shown that expression of Foxl2 activates the expression of $\alpha$-GSU in cellular and transgenic mice models. The demonstration that Foxl2 directly stimulates the $\alpha$-GSU promoter (Ellsworth et al., 2006) implicates Foxl2 even more directly in the regulation of gonadotropin secretion by the pituitary. Some data suggest that target specificity could stem from the interactions of Foxl2 with still unknown cofactors expressed in a tissue and/or cell specific manner (Nakamoto et al., 2006; Wang et al., 2007; Pannetier et al., 2006).

FoxL2 has also been shown to interact directly with the promoter of the Steroidogenesis Acute response (StAR) gene, to induce a robust inhibition of its basal transcriptional activity, in a dose dependant manner, through its Proline- and Alanine-rich carboxy-terminal region (Pisarska et al., 2004). StAR is a marker of late differentiation of granulosa cells in pre- 
ovulating follicles and catalyzes cholesterol translocation from the outer to the inner mitochondrial membrane, where it can subsequently be processed in its way to yield pregnenolone and enventually steroid hormones. This translocation of cholesterol is the ratelimiting step in steroidogenesis. In this study authors showed that the first $95 \mathrm{bp}$ upstream of the transcription start site of StAR promoter are sufficient to guarantee this repressive effect, and they showed by bandshift assays the direct interaction of FOXL2 with the promoter of StAR.

The role of FoxL2 in cholesterol metabolism and steroidogenesis in the ovary was further strengthened by the fact that it can up-regulate the expression of aromatase (CYP19), the enzyme responsible for the transformation of androgens to estrogens in granulosa cells. Moreover, it has been shown in various species that there is a strong correlation between aromatase and FoxL2 expression: co-localization of the two gene products has been detected by immunohistochemistry and in situ hybridization in chicken ovaries (Govoroun et al., 2004), rainbow trout gonads (Baron et al., 2004), medaka fish granulosa cells (Nakamoto et al., 2006), Nile tilapia gonads (Wang et al., 2007) and goat ovaries (Pannetier et al., 2006). Most of these studies have also documented a correlation between the profiles of the two genes at the mRNA level. Direct interaction of FoxL2 with the aromatase promoter, with a subsequent activation of the gene expression, was recently demonstrated for the Nile tilapia FoxL2 protein with the use heterologous cell sytems (Wang et al., 2007), as well as, more physiologically, for mammalian FoxL2 in ovine and human granulosa-derived cell lines (Pannetier et al., 2006).

The effects of the perturbation of the transcriptome of the granulosa-like cell line KGN by the overexpression of FOXL2 has been recently studied (Figure 2). The results suggest that FOXL2 participates in the regulation of cholesterol metabolism, reactive oxygen species detoxification pathways, inflammation and apoptotic processes (Batista et al., 2007). Indeed, FOXL2 appears to regulate cholesterol and steroid biosynthesis as several factors implicated in these pathways were modulated by FOXL2, namely, the peroxisome proliferator-activated receptor gamma coactivator 1 alpha (PPARGC1A) and NR5A2. PPARGC1A has been implicated in cholesterol metabolism through the enhancement of the Hepatocyte Nuclear Factor 4 (HNF-4) transcriptional activity (Yoon et al., 2001), and the interaction with the sterol regulatory element binding protein 1 (SREBP-1; Yamamoto et al., 2004). Moreover, as shown above, previous works have revealed that FOXL2 represses transcription of StAR, (Pisarska et al., 2004). On the other hand, FOXL2 participates as well in regulation of cholesterol transformation into steroid hormones by activating the aromatase (Baron et al., 2004; Pannetier 
et al., 2006; Wang et al., 2007). It is seemingly contradictory that aromatase and StAR, two key players of estrogen synthesis, are regulated by FOXL2 in opposite ways. However, it is known that follicular differentiation in vivo and in vitro is accompanied by increased expression of $3 \beta$ and 17ß-hydroxysteroid dehydrogenases (HSD3B1, HSD17B1 and HSD17B4) and aromatase even in the absence of StAR expression. For instance, cultured granulosa cells from small follicles accumulate estradiol and progesterone in the medium as a function of the time in culture (Sahmi et al., 2004). This increase parallels the amounts of mRNA encoding aromatase and the $\beta$-HSDs but not of P450scc (CYP11A1, also involved in early steps of steroid synthesis). Moreover, Sahmi et al., 2004 showed that the level of StAR mRNA did not change with the duration of culture and was not correlated with progesterone secretion. Another way to explain the apparent contradiction posed by the repression of cholesterol synthesis and the upregulation of estrogen synthesis could be the "two-cell, two-gonadotropin" hypothesis of regulation of estrogen synthesis in the human ovary. Indeed, ovarian steroidogenesis requires a tight communication between theca and granulosa cells. Androgen biosynthesis occurs in theca cells under the stimulation of LH (Ryan and Petro, 1966; Sasano et al., 1989). These androgens diffuse into the vascular granulosa compartment where, under FSH stimulation, they are aromatized to estrogens via the activity of the enzyme CYP19A1 (Bjersing, 1968). Thus, from this perspective cholesterol synthesis and early processing is more important in theca cells than in granulosa cells where aromatization of androgens takes place. The action of FOXL2 on these targets could explain, at least in part, the decreased levels of steroid hormones observed in BPES patients.

FOXL2 seems to play a role in the reactive oxygen species (ROS) detoxification pathways, as several of its members are upregulated by the overexpression of FOXL2, namely PPARGC1A, immediate early response 3 (IER3), and the mitochondrial mangenese superoxide dismutase $(M n S O D)$. PPARGC1A, in addition to its involvement in cholesterol metabolism, has been proposed to be a major transcriptional regulator of the mitochondrial detoxification system (Valle et al., 2005) and co-regulates the activation of several proteins participating in the cellular response to oxidative stress. For instance, knock-down of PPARGC1A results in a strong reduction of the levels of the antioxidant proteins such as MnSOD. Furthermore, chromatine immunoprecipitation assays showed that PPARGC1A is associated with the promoter region of the MnSOD gene (Valle et al., 2005). MnSOD was also induced by FOXL2 overexpression (Batista et al., 2007). Moreover, evidence for a direct interaction of FOXL2 with the MnSOD promoter has emerged. Thus, FOXL2 might activate MnSOD both directly 
and indirectly (i.e. via PPARGC1A, etc) in a kind of a coherent feed-forward loop. This architecture where $\mathrm{A}$ activates $\mathrm{B}$, and both $\mathrm{A}$ and $\mathrm{B}$ activate $\mathrm{C}$ appears frequently in known networks. Indeed, it is thought to detect persistent changes in environment (discrimination between noise and signal, oxidative stress in this case) (Mangan et al., 2003).

It is known that an increased resistance to oxidative stress correlates with longevity (Henderson and Johnson, 2001; and reviewed in Koubova and Guarente, 2003). Thus, FOXL2 could play a major role in the regulation of ovarian senescence since its mutation in BPES leads to phenotype similar to an accelerated ovarian ageing. Interestingly, FOXO3a, also a forkhead transcription factor somehow involved in ovarian development and function (Castrillon et al., 2003), has been shown to increase the levels of MnSOD in quiescent cells ensuring a protection against oxidative stress (Kops et al., 2002). Both FOXL2 and FOXO3a might cooperate to tune ovarian senescence and their potential cross-regulation is to be studied.

FOXL2 also appears to be implicated in the regulation of apoptosis, as it activates the transcription of several genes encoding factors involved in apoptotic processes (Batista et al., 2007). Beyond the activation of IER3, several anti-apoptotic genes, namely BCL2-related protein A1 (BCL2A1) and tumor necrosis factor alpha-induced protein 3 (TNFAIP3) were induced by the overexpression of FOXL2. On the other hand, FOXL2 appears to increase transcription of pro-apoptotic factors, such as an isoform of activating transcription factor 3 (ATF3). At a first glance, it is surprising to find this dual behavior for FOXL2. When Schmidt et al. (2004) published their results of the mouse KO model, FOXL2 was suggested to be an anti-apoptotic factor, given the massive apoptosis displayed by non differentiated granulosa cells (Schmidt et al., 2004). However, recent results suggest that FoxL2 could be able to mediate apopotosis, using the DEAD-box RNA Helicase DP103 as a co-activator (Lee et al., 2005). Indeed, FOXL2 overexpression increased DNA fragmentation, and decreased viability of CHO cells. The results of the transcriptional study of FOXL2 targets are in agreement with this ambivalent behavior of FOXL2 in apoptosis, but it is worth noticing that this character is not exclusive of FOXL2. Notably, FOXO factors also show this feature. For instance, in a number of cell types, particularly those of hematopoietic system, simple activation of FOXO factors are sufficient to trigger apoptosis (Brunet et al., 1999, Burgering et al., 2003, and references therein). However, in most other cell types, the activation of FOXO factors blocks cellular proliferation and drives cells into a quiescent state, providing them protection from oxidative stress through the activation of MnSOD (Kops et al., 2002) and catalase (Nemoto and 
Finkel, 2002). In the context of the ovary, the interaction of FOXL2 with other factors might define the fate of granulosa cells: differentiation and proliferation, or programmed cell death.

In addition, FOXL2 appears to be implicated in the regulation of players of inflammation processes such as several chemokine ligands and especially PTGS2/COX2. The latter is one of the two isoforms of cyclooxygenases involved in the synthesis of prostaglandins and catalyses the rate-limiting step of conversion of arachidonic acid into $\mathrm{PGH}_{2}$, which is subsequently converted to other prostaglandins by specific synthases (Smith and DeWitt, 1996). The activation of PTGS2 by FOXL2 overexpression is coherent with the findings of Lim et al. (1997) who described multiple reproductive failures in ovulation, fertilization, implantation, and decidualization, in the mouse model lacking PTGS2. PTGS2 participation in ovulation was suggested as this gene is transiently but strongly induced in granulosa cells following gonadotropin stimulation (Sirois et al., 1992; Sirois, 1994). Interestingly, in $\operatorname{Ptgs}^{-/}$mice ovulation was severely compromised with apparently normal follicular development and responsiveness to gonadotropin, even under a superovulatory stimulation (Lim et al., 1997). The fact that FOXL2 strongly activates PTGS2 points to an important role for prostaglandins in ovarian function. The fact that FOXL2 regulates the synthesis of prostaglandins in the ovary through the activation of PTGS2/COX2, and the upregulation of genes involved in inflammation, lends credence to the claims that ovulation is an inflammatory-like process, and suggests that FOXL2 might act very early during gonadal determination and all the way through the latest stages of follicular maturation and ovulation.

\section{Conclusion and perspectives.}

As already stated, FOXL2 is one of the earliest known markers of ovarian development but its function in development is far from being well established. It has been suggested that a single gene pathway, hinging on the Foxl2 transcription factor, might initiate and maintain sex differentiation in somatic cells of the mammalian ovary (Ottolenghi et al, 2007). There are hints supporting this claim. For instance, inactivation of Foxl2 induces the expression of testisspecific genes perinatally in female mice (Ottolenghi et al., 2005), when sexual reversion is no longer supposed to occur. However, the existence of an ovary perinatally in the Fox $l 2^{-/}$mouse is seemingly contradictory with the hypothesis of FOXL2 being an ovarian determining gene. Thus, it would be interesting to explore the impact on morphological and molecular markers of 
the expression of FOXL2 in the XY embryo, right before the onset of testicular determination. It is possible that FOXL2 overexpression in transgenic mice might lead to sex reversal (genetic males displaying a female phenotype). If this is so, the first clearcut evidence involving FOXL2 in ovarian determination would emerge. The alteration of the expression of known markers of testicular and ovarian development, such as SOX9 and some targets of FOXL2, has to be analysed in depth to produce a molecular portrait of this process.

Premature Ovarian Failure leads to hormonal perturbations, and infertility is the most critical consequence. However, in the majority of cases the aetiology of POF remains unknown. Several genes, including FOXL2 along with its transcriptional targets, are candidates to test in POF patients, and may be the basis of further molecular and functional studies. Their in-depth characterization will be essential to better understand ovarian function and to improve diagnostic and counseling of POF patients.

\section{Acknowledgments}

We thank an anonymous reviewer for helpful comments and I. Kamoun for careful reading of the revised MS. 


\section{References}

Aittomaki, K., Lucena, J.L., Pakarinen, P., Sistonen, P., Tapanainen, J., Gromoll, J., Kaskikari, R., Sankila, E.M., Lehvaslaiho, H., Engel, A.R., Nieschlag, E., Huhtaniemi, I., de la Chapelle, A., 1995. Mutation in the follicle-stimulating hormone receptor gene causes hereditary hypergonadotropic ovarian failure. Cell 82, 959-968.

Albrecht, A.N., Kornak, U., Boddrich, A., Suring, K., Robinson, P.N., Stiege, A.C., Lurz, R., Stricker, S., Wanker, E.E., Mundlos, S., 2004. A molecular pathogenesis for transcription factor associated poly-alanine tract expansions. Hum. Mol. Genet. 13, 2351-2359.

Amiel, J., Laudier, B., Attie-Bitach, T., Trang, H., de Pontual, L., Gener, B., Trochet, D., Etchevers, H., Ray, P., Simonneau, M., Vekemans, M., Munnich, A., Gaultier, C., Lyonnet, S., 2003. Polyalanine expansion and frameshift mutations of the paired-like homeobox gene PHOX2B in congenital central hypoventilation syndrome. Nat. Genet. 4, 459-461.

Bachetti, T., Matera, I., Borghini, S., Di Duca, M., Ravazzolo, R., Ceccherini, I., 2005. Distinct pathogenetic mechanisms for PHOX2B associated polyalanine expansions and frameshift mutations in congenital central hypoventilation syndrome. Hum. Mol. Genet. 14, 1815-1824.

Barlow, C., Hirotsune, S., Paylor, R., Liyanage, M., Eckhaus, M., Collins, F., Shiloh, Y., Crawley, J.N., Ried, T., Tagle, D., Wynshaw-Boris, A., 1996. Atm-deficient mice: a paradigm of ataxia telangiectasia. Cell 86, 159-171.

Baron, D., Cocquet, J., Xia, X., Fellous, M., Guiguen, Y. Veitia, R. A., 2004. An evolutionary and functional analysis of FoxL2 in rainbow trout gonad differentiation. J. Mol. Endocrinol. 33, 705-715.

Batista, F., Vaiman, D, Dausset, J., Fellous, M. Veitia, R., 2007. Potential targets of FOXL2, a transcription factor involved in craniofacial and follicular development, identified by transcriptomics. Proc. Nat. Acad. Sci. USA 104, 3330-3335.

Beysen, D., Raes, J., Leroy, B.P., Lucassen, A., Yates, J.R., Clayton-Smith, J., Ilyina, H., Brooks, S.S., Christin-Maitre, S., Fellous, M., Fryns, J.P., Kim, J.R., Lapunzina, P., Lemyre, E., Meire, F., Messiaen, L.M., Oley, C., Splitt, M., Thomson, J., Van de Peer, Y., Veitia, R.A., De Paepe, A., De Baere, E., 2005. Deletions involving long-range conserved nongenic 
sequences upstream and downstream of FOXL2 as a novel disease-causing mechanism in blepharophimosis syndrome. Am. J. Hum. Genet.77, 205-218.

Bione, S., Sala, C., Manzini, C., Arrigo, G., Zuffardi, O., Banfi, S., Borsani, G., Jonveaux, P., Philippe, C., Zuccotti, M., Ballabio, A., Toniolo, D., 1998. A human homologue of the Drosophila melanogaster diaphanous gene is disrupted in a patient with premature ovarian failure: evidence for conserved function in oogenesis and implications for human sterility. Am J. Hum. Genet. 62, 533-541.

Bjersing, L., 1968. On the morphology and endocrine function of granulosa cells in ovarian follicles and corpora lutea. Biochemical, histochemical, and ultrastructural studies on the porcine ovary with special reference to steroid hormone synthesis. Acta Endocrinol. 125, 1-23.

Brais, B., Bouchard, J.P., Xie, Y.G., Rochefort, D.L., Chretien, N., Tome, F.M., Lafreniere, R.G., Rommens, J.M., Uyama, E., Nohira, O., Blumen, S., Korczyn, A.D., Heutink, P., Mathieu, J., Duranceau, A., Codere, F., Fardeau, M., Rouleau, G.A., 1998. Short GCG expansions in the PABP2 gene cause oculopharyngeal muscular dystrophy. Nat. Genet. 18, 164-167.

Brown, L.Y., Odent, S., David, V., Blayau, M., Dubourg, C., Apacik, C., Delgado, M.A., Hall, B.D., Reynolds, J.F., Sommer, A., Wieczorek, D., Brown, S.A., Muenke, M., 2001. Holoprosencephaly due to mutations in ZIC2: alanine tract expansion mutations may be caused by parental somatic recombination. Hum. Mol. Genet. 10, 791-796.

Brunet, A., Bonni, A., Zigmond, M.J., Lin, M.Z., Juo, P., Hu, L.S., Anderson, M.J., Arden K.C., Blenis, J. Greenberg, M.E., 1999. Akt promotes cell survival by phosphorylating and inhibiting a Forkhead transcription factor. Cell 96, 857-868.

Burgering, B. M. Medema, R.H., 2003. Decisions on life and death: FOXO Forkhead transcription factors are in command when PKB/Akt is off duty. J. Leukoc. Biol. 73, 689-701.

Caburet, S., Demarez, A., Moumné, L., Fellous, M., De Baere, E., Veitia, R.A., 2004. A recurrent polyalanine expansion in the transcription factor FOXL2 induces extensive nuclear and cytoplasmic protein aggregation. J. Med. Genet. 41, 932-936. 
Calado, A., Tome, F.M., Brais, B., Rouleau, G.A., Kuhn, U., Wahle, E., Carmo-Fonseca, M., 2000. Nuclear inclusions in oculopharyngeal muscular dystrophy consist of poly(A) binding protein 2 aggregates which sequester poly(A) RNA. Hum. Mol. Genet. 9, 2321-2328.

Castrillon, D.H., Miao, L., Kollipara, R., Horner, J.W., DePinho, R.A., 2003. Suppression of ovarian follicle activation in mice by the transcription factor Foxo3a. Science. 301, 215-218.

Chang, C.C., Gould, S.J., 1998. Phenotype-genotype relationships in complementation group 3 of the peroxisome-biogenesis disorders. Am. J. Hum. Genet. 63, 1294-1306.

Christin-Maitre, S., Vasseur, C., Portnoi, M.F., Bouchard, P., 1998. Genes and premature ovarian failure. Mol. Cell. Endocrinol. 145, 75-80.

Clark, K.L., Halay, E.D., Lai, E., Burley, S.K., 1993. Co-crystal structure of the HNF-3/fork head DNA-recognition motif resembles histone H5. Nature. 364, 412-420.

Cocquet, J., Pailhoux, E., Jaubert, F., Servel, N., Xia, X., Pannetier, M., De Baere, E., Messiaen, L., Cotinot, C., Fellous, M., Veitia, R.A. 2002 Evolution and expression of FOXL2. J. Med. Genet. 39, 916-21.

Cocquet, J., De Baere, E., Gareil, M., Pannetier, M., Xia, X., Fellous, M. \& Veitia, R. A. 2003 Structure, evolution and expression of the FOXL2 transcription unit. Cytogenet. Genome Res. 101, 206-211.

Corbeil-Girard, L.P., Klein, A.F., Sasseville, A.M., Lavoie, H., Dicaire, M.J., Saint-Denis, A., Pagé, M., Duranceau, A., Codère, F., Bouchard, J.P., Karpati, G., Rouleau, G.A., Massie, B., Langelier, Y., Brais, B., 2005 PABPN1 overexpression leads to upregulation of genes encoding nuclear proteins that are sequestered in oculopharyngeal muscular dystrophy nuclear inclusions. Neurobiol Dis. 18, 551-567.

Crisponi, L., Deiana, M., Loi, A., Chiappe, F., Uda, M., Amati, P., Bisceglia, L., Zelante, L., Nagaraja, R., Porcu, S., Ristaldi, M.S., Marzella, R., Rocchi, M., Nicolino, M., LienhardtRoussie, A., Nivelon, A., Verloes, A., Schlessinger, D., Gasparini, P., Bonneau, D., Cao, A., Pilia, G., 2001. The putative forkhead transcription factor FOXL2 is mutated in blepharophimosis/ptosis/epicanthus inversus syndrome. Nat. Genet. 27, 159-166. 
Culbertson, M.R., 1999. RNA surveillance. Unforeseen consequences for gene expression, inherited genetic disorders and cancer. Trends Genet. 15, 74-80.

De Baere, E., Dixon, M.J., Small, K.W., Jabs, E.W., Leroy, B.P., Devriendt, K., Gillerot, Y., Mortier, G., Meire, F., Van Maldergem, L., Courtens, W., Hjalgrim, H., Huang, S., Liebaers, I., Van Regemorter, N., Touraine, P., Praphanphoj, V., Verloes, A., Udar, N., Yellore, V., Chalukya, M., Yelchits, S., De Paepe, A., Kuttenn, F., Fellous, M., Veitia, R., Messiaen, L., 2001. Spectrum of FOXL2 gene mutations in blepharophimosis-ptosis-epicanthus inversus (BPES) families demonstrates a genotype-phenotype correlation. Hum. Mol. Genet. 10, 15911600 .

De Baere, E., Beysen, D., Oley, C., Lorenz, B., Cocquet, J., De Sutter, P., Devriendt, K., Dixon, M., Fellous, M., Fryns, J.P., Garza, A., Jonsrud, C., Koivisto, P.A., Krause, A., Leroy, B.P., Meire, F., Plomp, A., Van Maldergem, L., De Paepe, A., Veitia, R., Messiaen, L., 2003. FOXL2 and BPES: mutational hotspots, phenotypic variability, and revision of the genotypephenotype correlation. Am. J. Hum. Genet. 72, 478-487.

Dierich, A., Sairam, M.R., Monaco, L., Fimia, G.M., Gansmuller, A., LeMeur, M., SassoneCorsi, P., 1998. Impairing follicle-stimulating hormone (FSH) signaling in vivo: targeted disruption of the FSH receptor leads to aberrant gametogenesis and hormonal imbalance. Proc. Natl. Acad. Sci. U S A. 95, 13612-13627.

Ellsworth, B.S., Burn, A.T., Escudero, K.W., Duval, D.L., Nelson, S.E., Clay, C.M., 2003. The gonadotropin releasing hormone $(\mathrm{GnRH})$ receptor activating sequence (GRAS) is a composite regulatory element that interacts with multiple classes of transcription factors including Smads, AP-1 and a forkhead DNA binding protein. Mol. Cell. Endocrinol. 206, 93-111.

Ellsworth, B.S., Egashira, N., Haller, J.L., Butts, D.L., Cocquet, J., Clay, C.M., Osamura, R.Y., Camper, S.A., 2006. FoxL2 in the Pituitary: Molecular, Genetic, and Developmental Analysis. Mol. Endocrinol. 20, 2796-2805.

Goswami, D., Conway, G.S., 2005. Premature ovarian failure. Hum. Reprod. Update. 11, 391410.

Govoroun, M.S., Pannetier, M., Pailhoux, E., Cocquet, J., Brillard, J.P., Couty, I., Batellier, F., Cotinot, C., 2004. Isolation of chicken homolog of the FOXL2 gene and comparison of its 
expression patterns with those of aromatase during ovarian development. Dev. Dyn. 231, 859870.

Hellen, C.U., Sarnow, P., 2001. Internal ribosome entry sites in eukaryotic mRNA molecules. Genes Dev. 15, 1593-1612.

Henderson, S.T. and Johnson, T.E., 2001. Daf-16 integrates developmental and environmental inputs to mediate aging in the nematode Caenorhabditis elegans. Current Biology 11, 19751980.

Heppner Goss, K., Trzepacz, C., Tuohy, T.M., Groden, J., 2002. Attenuated APC alleles produce functional protein from internal translation initiation. Proc. Natl. Acad. Sci. U S A. 99, 8161-8166.

Howard, M.T., Malik, N., Anderson, C.B., Voskuil, J.L., Atkins, J.F., Gibbons, R.J., 2004. Attenuation of an amino-terminal premature stop codon mutation in the ATRX gene by an alternative mode of translational initiation. J. Med. Genet. 41, 951-956.

Kops, G. J., Dansen, T. B., Polderman, P. E., Saarloos, I., Wirtz, K. W., Coffer, P. J., Huang, T. T., Bos, J. L., Medema, R. H. Burgering, B. M., 2002. Forkhead transcription factor FOXO3a protects quiescent cells from oxidative stress. Nature 419, 316-321.

Koubova J and Guarente L., 2003. How does calorie restriction work? Genes and Development $17,313-321$

Kozak, M., 1987. At least six nucleotides preceding the AUG initiator codon enhance translation in mammalian cells. J. Mol. Biol. 196, 947-950.

Kozak, M., 1989. The scanning model for translation: an update. J. Cell. Biol. 108, 229-241.

Laumonnier, F., Ronce, N., Hamel, B.C., Thomas, P., Lespinasse, J., Raynaud, M., Paringaux, C., Van Bokhoven, H., Kalscheuer, V., Fryns, J.P., Chelly, J., Moraine, C., Briault, S., 2002. Transcription factor SOX3 is involved in X-linked mental retardation with growth hormone deficiency. Am. J. Hum. Genet. 71, 1450-1455.

Lee K, Pisarska MD, Ko JJ, Kang Y, Yoon S, Ryou SM, Cha KY, Bae J, 2005. Transcriptional factor FoxL2 interacts with DP103 and induces apoptosis. Biochem. and Biophys. Res. Com. $336,876-881$. 
Lim, H., Paria, B. C., Das, S. K., Dinchuk, J. E., Langenbach, R., Trzaskos, J. M. Dey, S. K., 1997. Multiple Female Reproductive Failures in Cyclooxygenase 2-Deficient Mice. Cell 91, 197-208.

Mangan, S., Zaslaver, A., Alon, U., 2003. The coherent feed-forward loop serves as a signsensitive delay element in transcription networks. J. Molecular Biology 334, 197-204.

Maser, R.S., Zinkel, R., Petrini, J.H., 2001. An alternative mode of translation permits production of a variant NBS1 protein from the common Nijmegen breakage syndrome allele. Nat. Genet. 27, 417-421.

Moumné, L., Fellous, M., Veitia, R.A., 2005. Deletions in the polyAlanine-containing transcription factor FOXL2 lead to intranuclear aggregation. Hum. Mol. Genet. 14, 3557-3564.

Mundlos, S., Otto, F., Mundlos, C., Mulliken, J.B., Aylsworth, A.S., Albright, S., Lindhout, D., Cole, W.G., Henn, W., Knoll, J.H., Owen, M.J., Mertelsmann, R., Zabel, B.U., Olsen, B.R., 1997. Mutations involving the transcription factor CBFA1 cause cleidocranial dysplasia. Cell 89, 773-779.

Muragaki, Y., Mundlos, S., Upton, J., Olsen, BR., 1996. Altered growth and branching patterns in synpolydactyly caused by mutations in HOXD13. Science 272, 548-551.

Nakamoto M, Matsuda M, Wang DS, Nagahama Y, Shibata N, 2006. Molecular cloning and analysis of gonadal expression of FoxL2 in the medaka, Oryzias latipes. Biochem. and Biophys. Res. Com. 344, 353-361.

Nallathambi, J., Moumné, L., De Baere, E., Beysen, D., Usha, K., Sundaresan, P., Veitia, R.A., 2007. A novel polyalanine expansion in FOXL2: the first evidence for a recessive form of the blepharophimosis syndrome (BPES) associated with ovarian dysfunction. Hum. Genet. 121, 107-112.

Nasrallah, I.M., Minarcik, J.C., Golden, J.A., 2004. A polyalanine tract expansion in Arx forms intranuclear inclusions and results in increased cell death. J. Cell. Biol. 167, 411-416.

Nemoto, S., Finkel, T., 2002. Redox regulation of forkhead proteins through a p66shcdependent signaling pathway. Science 295, 2450-2452.

Ottolengh,i C., Omari, S., Garcia-Ortiz, J.E., Uda, M., 
Crisponi, L., Forabosco, A., Pilia, G., Schlessinger, D., 2005. Foxl2 is required for commitment to ovary differentiation. Hum Mol Genet. 15, 2053-2062.

Ottolenghi, C., Uda. M., Crisponi, L., Omari, S., Cao, A., Forabosco, A., Schlessinger, D., 2007. Determination and stability of sex. Bioessays. 29, 15-25.

Ozisik, G., Mantovani, G., Achermann, J.C., Persani, L., Spada, A., Weiss, J., Beck-Peccoz, P., Jameson, J.L., 2003. An alternate translation initiation site circumvents an amino-terminal DAX1 nonsense mutation leading to a mild form of X-linked adrenal hypoplasia congenita. J. Clin. Endocrinol. Metab. 88, 417-423.

Pannetier, M., Fabre, S., Batista, F., Kocer, A., Renault, L., Jolivet, G., Mandon-Pepin, B., Cotinot, C., Veitia, R.A., Pailhoux, E., 2006. FoxL2 activates P450 aromatase gene transcription: towards a better characterization of the early steps of mammalian ovarian development. J. Mol. Endocrinol. 36, 399-413.

Paulson, H.L., 1999. Protein fate in neurodegenerative proteinopathies: polyglutamine diseases join the (mis)fold. Am. J. Hum. Genet. 64, 339-345.

Pisarska, M.D., Bae, J., Klein, C., Hsueh, A.J.W., 2004. Forkhead L2 is expressed in the ovary and represses the promoter activity of the Steroidogenic acute regulatory gene. Endocrinology, $145,3424-3433$.

Powell, C.M., Taggart, R.T., Drumheller, T.C., Wangsa, D., Qian, C., Nelson, L.M., White, B.J., 1994. Molecular and cytogenetic studies of an X;autosome translocation in a patient with premature ovarian failure and review of the literature. Am. J. Med. Genet. 52, 19-26.

Prueitt, R.L., Ross, J.L., Zinn, A.R. 2000. Physical mapping of nine Xq translocation breakpoints and identification of XPNPEP2 as a premature ovarian failure candidate gene. Cytogenet. Cell. Genet. 89, 44-50.

Puel, A., Reichenbach, J., Bustamante, J., Ku, C.L., Feinberg, J., Doffinger, R., Bonnet, M., Filipe-Santos, O., Beaucoudrey, L., Durandy, A., Horneff, G., Novelli, F., Wahn, V., Smahi, A., Israel, A., Niehues, T., Casanova, J.L., 2006. The NEMO mutation creating the mostupstream premature stop codon is hypomorphic because of a reinitiation of translation. Am. J. Hum. Genet. 78, 691-701. 
Raile, K., Stobbe, H., Trobs, R.B., Kiess, W., Pfaffle, R., 2005. A new heterozygous mutation of the FOXL2 gene is associated with a large ovarian cyst and ovarian dysfunction in an adolescent girl with blepharophimosis/ptosis/epicanthus inversus syndrome. Eur. J. Endocrinol. $153,353-358$.

Ramirez-Castro, J.L., Pineda-Trujillo, N., Valencia, A.V., Muneton, C.M., Botero, O., Trujillo, O., Vasquez, G., Mora, B.E., Durango, N., Bedoya, G., Ruiz-Linares, A., 2002. Mutations in FOXL2 underlying BPES (types 1 and 2) in Colombian families. Am. J. Med. Genet. 113, 4751.

Romanelli, M.G., Tato, L., Lorenzi, P., Morandi, C., 2003. Nuclear localization domains in human thyroid transcription factor 2. Biochim Biophys Acta. 1643, 55-64.

Ryan, K. J. Petro, Z., 1966. Steroid biosynthesis by human ovarian granulosa and thecal cells. J. Clin. Endocrinol. Metab. 26, 46-52.

Sahmi, M., Nicola, E.S., Silva, J.M. Price, C.A., 2004. Expression of 17beta- and 3betahydroxysteroid dehydrogenases and steroidogenic acute regulatory protein in non-luteinizing bovine granulosa cells in vitro.Mol. Cell. Endocrinol. 223, 43-54.

Sasano, H., Okamoto, M., Mason, J. I., Simpson, E. R., Mendelson, C.R., Sasano, N. Silverberg, S. G., 1989. Immunohistochemical studies of steroidogenic enzymes (aromatase, 17 alpha-hydroxylase and cholesterol side-chain cleavage cytochromes P-450) in sex cord-stromal tumors of the ovary. Hum. Pathol. 20, 452-457.

Schmidt, D., Ovitt, C. E., Anlag, K., Fehsenfeld, S., Gredsted, L., Treier, A. C. Treier, M., 2004. The murine winged-helix transcription factor Foxl2 is required for granulosa cell differentiation and ovary maintenance. Development 131, 933-942.

Sirois, J., Simmons, D.L., Richards, J.S., 1992. Hormonal regulation of messenger ribonucleic acid encoding a novel isoform of prostaglandin endoperoxide $\mathrm{H}$ synthase in rat preovulatory follicles. Induction in vivo and in vitro. J. Biol. Chem. 267, 11586-11592.

Sirois, J., 1994. Induction of prostaglandin endoperoxide synthase-2 by human chorionic gonadotropin in bovine preovulatory follicles in vivo. Endocrinology 135, 841-848. 
Smith, W.L., Dewitt, D.L. 1996. Prostaglandin endoperoxide H synthases-1 and -2. Adv. Immunol. 62, 167-215.

Stromme, P., Mangelsdorf, M.E., Shaw, M.A., Lower, K.M., Lewis, S.M., Bruyere, H., Lutcherath, V., Gedeon, A.K., Wallace, R.H., Scheffer, I.E., Turner, G., Partington, M., Frints, S.G., Fryns, J.P., Sutherland, G.R., Mulley, J.C., Gecz, J., 2002. Mutations in the human ortholog of Aristaless cause X-linked mental retardation and epilepsy. Nat. Genet. 30, 441-445.

Touraine, P., Beau, I., Gougeon, A., Meduri, G., Desroches, A., Pichard, C., Detoeuf, M., Paniel, B., Prieur, M., Zorn, J.R., Milgrom, E., Kuttenn, F., Misrahi, M., 1999. New natural inactivating mutations of the follicle-stimulating hormone receptor: correlations between receptor function and phenotype. Mol. Endocrinol. 13, 1844-1854.

Trochet, D., Hong, S.J., Lim, J.K., Brunet, J.F., Munnich, A., Kim, K.S., Lyonnet, S., Goridis, C., Amiel, J., 2005. Molecular consequences of PHOX2B missense, frameshift and alanine expansion mutations leading to autonomic dysfunction. Hum. Mol. Genet. 14, 3697-3708.

Uda, M., Ottolenghi, C., Crisponi, L., Garcia, J. E., Deiana, M., Kimber, W., Forabosco, A., Cao, A., Schlessinger, D. Pilia, J., 2004. Foxl2 disruption causes mouse ovarian failure by pervasive blockage of follicle development. Hum. Mol. Genet. 13, 1171-1181.

Utsch, B., Becker, K., Brock, D., Lentze, M.J., Bidlingmaier, F., Ludwig, M., 2002. A novel stable polyalanine [poly(A)] expansion in the HOXA13 gene associated with hand-foot-genital syndrome: proper function of poly(A)-harbouring transcription factors depends on a critical repeat length? Hum. Genet. 110, 488-494.

Veitia, R.A., 2003 RA sigmoidal transcriptional response: cooperativity, synergy and dosage effects. Biol Rev Camb Philos Soc. 78, 149-170.

Valle, I., Alvarez-Barrientos, A., Arza, E., Lamas, S., Monsalve, M., 2005. PGC-1a regulates the mitochondrial antioxidant defense system in vascular endothelial cells. Cardiovascular Res. $66,562-573$.

Wang, D.S., Kobayashi, T., Zhou, L.Y., Paul-Prasanth, B., Ijiri, S., Okubo, K., Morohashi, K.I., Nagahama, Y., 2007. FoxL2 up-regulate aromatase gene transcription in a female-specific manner by binding to the promoter as well as interacting with Ad4BP/SF-1. Mol. Endocrinol. 21, 712-725. 
Wilkinson, M.F., Shyu, A.B., 2002. RNA surveillance by nuclear scanning? Nat. Cell. Biol. 4 E144-147.

Yamamoto, T., Shimano, H., Nakagawa, Y., Ide, T., Nahagi, N., Matsuzaka, T., Nakakuki, M., Takahashi, A., Suzuki, H., Sone H., Toyoshima, H., Sato R., Yamada, N., 2004. SREBP-1 Interacts with Hepatocyte Nuclear Factor- $4 \alpha$ and Interferes with PGC-1 Recruitment to Suppress Hepatic Gluconeogenic Genes. J. Biol. Chem. 279, 12027-12035.

Yoon, J.C., Puigserver, Chen, G., Donovan, J., Wu, Z., Rhee, J., Adelmant, G., Stafford, J., Khan, C.R., Graner, D.K., Newgard, C.B., Spiegelman, G.M. 2001. Control of hepatic gluconeogenesis through the transcriptional coactivator PGC-1. Nature 413, 131-138.

Zhang, J., Maquat, L.E., 1997. Evidence that translation reinitiation abrogates nonsensemediated mRNA decay in mammalian cells. EMBO J. 16, 826-833.

Zlotogora, J., Sagi, M., Cohen, T. 1983. The blepharophimosis, ptosis, and epicanthus inversus syndrome: delineation of two types. Am. J. Hum. Genet. 35, 1020-1027.

Zoppi, S., Wilson, C.M., Harbison, M.D., Griffin, J.E., Wilson, J.D., McPhaul, M.J., Marcelli, M., 1993. Complete testicular feminization caused by an amino-terminal truncation of the androgen receptor with downstream initiation. J. Clin. Invest. 91, 1105-1112. 
Figure Legends.

1) Examples of protein aggregation induced by FOXL2 mutations. FOXL2-Ala24 (expansion of the polyAla). FOXL2-Stop19 (N-terminally truncated FOXL2) both proteins are fused to the GFP.

2) Summary of pathways involving FOXL2 (modified from Batista et al. 2007). Red stands for induction and green for repression. It cannot be ruled out that FOXL2 overexpression might lead to paradoxical results in some cases (i.e. induction instead of repression) by altering the stoichiometry of the transcriptional complexes. 


\section{Hoechst}

GFP

\section{FOXI2-WT}

FOXI2-Ala24

\section{FOXL2-Stop19}


Pituitary (GnRHR)
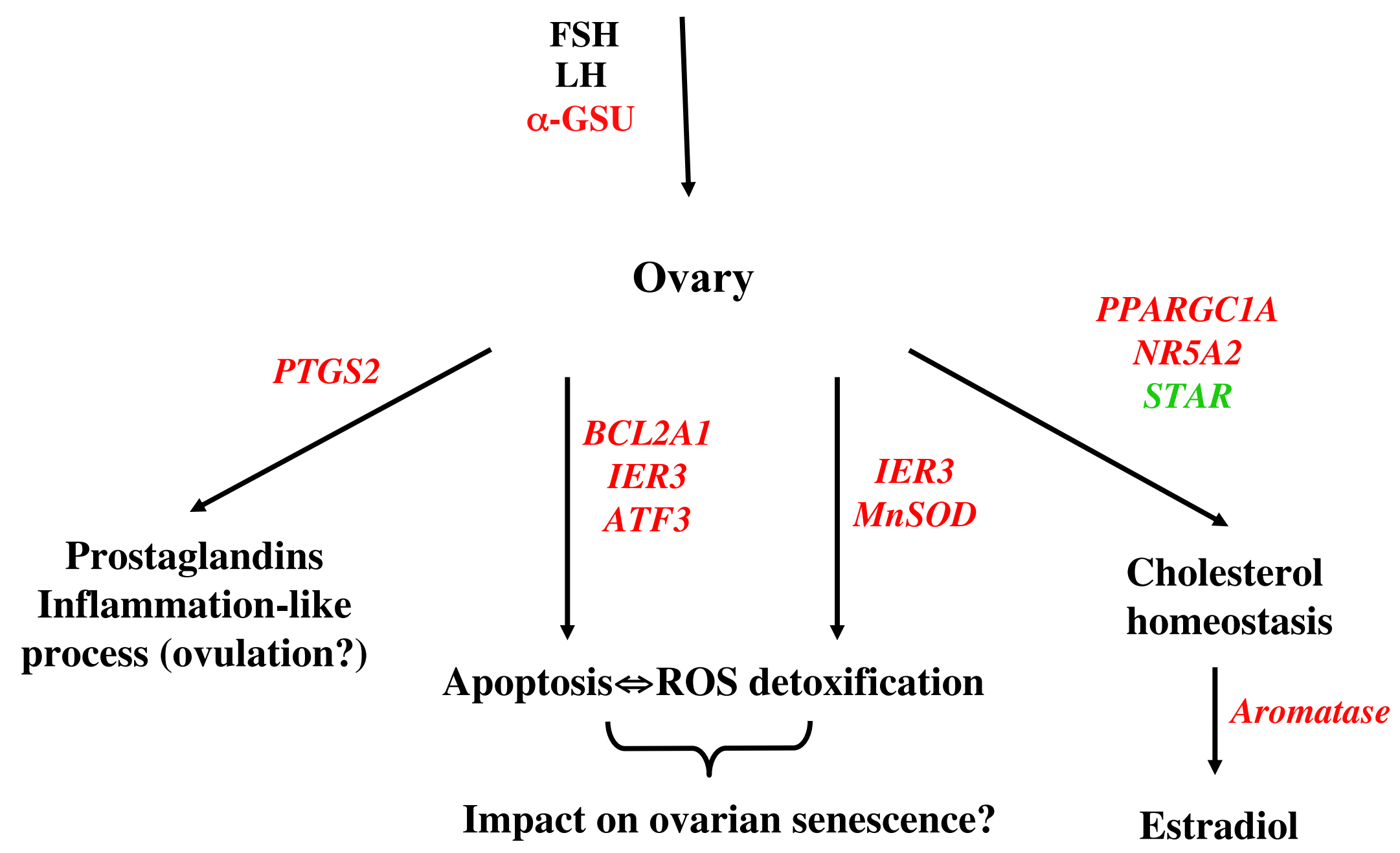